\title{
UM ESTUDO SOBRE O DESENVOLVIMENTO NO BRASIL DA COOPERAÇÃO UNIVERSIDADE-EMPRESA - INTERAÇÃO ENTRE A INSTITUIÇÃO DE ENSINO SUPERIOR DE TECNOLOGIA E A MICRO E PEQUENA EMPRESA
}

\author{
A study on the development of cooperation \\ University-company in Brazil - The interaction \\ between the institution of higher education in \\ technology and micro and small business
}

Envio 05.08.09 / Aceite 23.11.09

\author{
Nilson Carlos Duarte da Silva ${ }^{1}$ \\ Antonio Carlos Giuliani ${ }^{2}$
}

\section{Resumo}

O presente estudo teve como objetivo analisar o desenvolvimento, no Brasil, das relações de cooperação entre as instituições de ensino superior, principalmente aquelas dedicadas ao ensino tecnológico, e as micro e pequenas empresas. Nas micro e pequenas empresas, concentra-se grande parte da mão de obra ocupada do mercado de trabalho. Essas empresas são as que mais precisam de atenção para poder melhorar a produtividade e induzir a maior formalização de mão de obra ocupada, de modo a integrá-las ao setor contemporâneo da economia. Nesse contexto, faz-se necessário estudar os mecanismos existentes de cooperação universidade-empresa. A partir da análise de material coletado em livros, dissertações, demais pesquisas publicadas, bem como busca na Internet, foi possível concluir que as empresas e as universidades possuem culturas diferentes e, por conseguinte, missões distintas. Porém o fato de atuarem em projetos de cooperação não implica mudança da missão, mas sim entendimento de que cada participante pode complementar o outro. Essa aliança trará somente benefícios às universidades, às micro e pequenas empresas e ao País como um todo.

Palavras-chave: Ensino Tecnológico; Micro e Pequenas Empresas; Cooperação UniversidadeEmpresa.

\footnotetext{
${ }^{1}$ Doutorando em Engenharia de Produção pela FEAU-UNIMEP, professor-responsável pela implantação do campus (Diretor) da Faculdade de Tecnologia de Praia Grande. E-mail: nilson@fatecpg.com.br

${ }^{2}$ Doutor em Administração Escolar pela UNIMEP, coordenador do Mestrado Profissional em Administração da FGNUNIMEP. E-mail: cgiuliani@unimep.br
} 


\begin{abstract}
This study aimed to analyze the development in Brazil of the cooperation relations between higher education institutions, especially those dedicated to technology education, and micro and small companies. In micro and small enterprises are concentrate much of the workforce employed in the labor market. These companies are those that need attention in order to improve productivity and lead to greater formalization of the labor force employed in order to integrate them into the modern sector of the economy. In this context, it is necessary to study the mechanisms of cooperation between universities and business. From the analysis of material from books, dissertations, other published research, as well as Internet search, we concluded that, companies and universities have different cultures and therefore different missions. However, the fact of acting in cooperation projects does not mean changing the mission, but the understanding that each participant can complement each other. This alliance will bring only benefits to universities and micro and small enterprises and the country as a whole.

Keywords: Technological Education; Micro and Small Companies; Cooperation UniversityEnterprise.
\end{abstract}

\title{
1 Introdução
}

Na última década, testemunhou-se a evolução dos cursos superiores de tecnologia no sistema educacional de quase todo o país, o que foi constatado pelo Instituto Nacional de Estudos e Pesquisas Educacionais Anísio Teixeira, que registrou um crescimento de $74 \%$ entre 2000 e 2002 (de 364 para 636 cursos). Esse fenômeno, dentro das instituições de ensino superior, pode ser explicado por diferentes razões, mas decorre, sobretudo, da necessidade de qualificar os alunos para atender às demandas ocasionadas pela tecnologia.

Dentro de um cenário de grandes transformações econômicas, políticas e tecnológicas e, consequentemente, do mercado de trabalho, vem-se consolidando, no Brasil, a necessidade de um profissional cada vez mais qualificado e envolvido com os avanços das ciências e das técnicas. No contexto de um ambiente caracterizado por constante e acelerado movimento, coloca-se, claramente, um desafio relativo à qualificação das pessoas para atuarem de forma efetiva na sociedade como agentes de mudanças e como parceiros na criação de novas possibilidades.

O conhecimento gerado por uma nação só será convertido em riqueza e desenvolvimento social, se houver um forte relacionamento com alguns agentes institucionais geradores e aplicadores desse conhecimento. As empresas, as universidades e o governo são os principais componentes dessa interação, formando um sistema nacional de geração e apropriação de conhecimento (CRUZ, 2000).

A participação econômica da pequena empresa no Brasil é de $43 \%$ no total de empregos, e 98,23\% no total de empresas. Portanto, as micro e pequenas empresas são setores estratégicos da economia do País e representam fatores-chave para a criação de empregos, para a melhoria da distribuição de rendas e para o desenvolvimento da sociedade. Mas, infelizmente, muitas não conseguem completar três anos de atividade, e pouquíssimas sobrevivem mais de cinco anos, ou seja, a taxa de mortalidade é elevadíssima (SEBRAE, 2008).

Nas micro e pequenas empresas, concentra-se grande parte da mão de obra ocupada do mercado de trabalho. Essas empresas são as que mais precisam de atenção para poderem 
melhorar a produtividade e induzir a maior formalização de mão de obra ocupada, de modo a integrá-las ao setor contemporâneo da economia.

A motivação para esta pesquisa surgiu da necessidade de se procurar investigar de que forma a cooperação entre institutos superiores de tecnologia e micro e pequenas empresas poderiam contribuir para melhorar o desenvolvimento tecnológico desse tipo de empresa.

Nesse contexto, faz-se necessário estudar os mecanismos existentes de cooperação universidade-empresa, buscando elementos que respondam aos seguintes questionamentos: Os mecanismos existentes de cooperação universidade-empresa podem ser aplicados às micro e pequenas empresas? Quais os motivos que levam as empresas a procurarem a universidade para a realização de parcerias? Como o estágio supervisionado pode ser um mecanismo de cooperação entre a instituição de ensino superior de tecnologia e a micro e pequena empresa?

Essas indagações foram o ponto de partida para uma busca às respostas que pudessem esclarecer qual o estado da arte na cooperação entre instituição de ensino superior de tecnologia e a micro e pequena empresa.

\section{Objetivos}

O objetivo geral desta pesquisa é analisar a relação universidade-empresa, estudando sua evolução histórica, desde os primórdios da educação no Brasil, até o estágio atual, bem como as modalidades de relacionamento existentes e que regem essa interação.

Como objetivos específicos, pretende-se:

a) apresentar a evolução da Educação Profissional no Brasil;

b) compreender como se processa a relação Universidade-Empresa, identificando os principais mecanismos utilizados nessa interação.

\section{Metodologia}

Para a construção do referencial teórico, buscaram-se informações em dados secundários, por meio de pesquisa em livros, dissertações, teses, artigos científicos, além de busca na Internet.

\section{Desenvolvimento}

Uma das funções da universidade é a produção de conhecimento, porém esse conhecimento, se associado ao desenvolvimento e à abertura de caminhos para o desenvolvimento da tecnologia, não estará se desviando da responsabilidade para com a pesquisa básica.

Acredita-se que o papel da universidade deve ser muito mais amplo do que o de fornecer à empresa profissionais competentes que auxiliem em suas atividades.

Para Zagottis (1995, p. 77), a universidade é entendida como um núcleo de progresso e esse conceito gerou a universidade do século XX, transformando-a no mais importante e efetivo entre todos os núcleos de progresso de que as sociedades podem dispor. Nessa formulação, a universidade tem por finalidade a educação, a criação e a organização de conhecimentos, por meio da pesquisa científica e da pesquisa tecnológica, e a extensão de serviços à sociedade, como, por exemplo, por meio de hospitais universitários e de interação com o setor produtivo.

Segundo Torkomian (1997, p. 23), desde a implantação das universidades brasileiras, priorizaram-se apenas as atividades de ensino e pesquisa. 
Por volta do século XVII, enquanto as universidades desempenhavam atividades de ensino, as pesquisas eram realizadas, desvinculadamente, em associações com o intuito de desenvolver a ciência voltada ao crescimento industrial e comercial. "Dessa forma, a difusão do conhecimento decorrente do desenvolvimento técnico ocorreu sem a participação da universidade" (MAIA, 2005, p. 90).

Esse conceito demarca a primeira revolução acadêmica ocorrida no século XIX, quando à função de ensino foi acrescida a atividade de pesquisa, ou seja, a pesquisa em Ciência e Tecnologia (C\&T) passa a fazer parte da esfera acadêmica. O modelo de universidade que representou o rompimento com o padrão tradicional foi a Universidade de Berlim.

Pode-se atribuir que a universidade passa uma fase chamada de Segunda Revolução Acadêmica, como ressalta Brisolla (1992), quando assume a necessidade de se alicerçar no tripé "ensino, pesquisa e extensão". A extensão envolve o desenvolvimento de atividades educativas, culturais e científicas junto à comunidade externa, viabilizando uma relação transformadora entre a universidade e a sociedade.

Só recentemente a maioria das universidades públicas brasileiras vêm implementando ações que dão maior atenção a seu papel social, configurando um reposicionamento das atividades de extensão dentre as atividades acadêmicas.

Muitos são os obstáculos estruturais que interferem no processo de valorização das atividades de extensão, dentre os quais podem-se destacar (PROEX/UFSCAR, 1994, p. 3):

- gênese da universidade brasileira como escola para formação de elites;

- desenvolvimento posterior da universidade com ênfase na pesquisa básica e pouco compromisso com os problemas imediatos da população;

- papel político assumido pela universidade, principalmente na década de 1960, de resistência ao regime de ditadura militar;

- ausência de uma política de desenvolvimento e fortalecimento da universidade pública, com verbas parcas até para o desenvolvimento das atividades de ensino;

- distância entre as teorias estudadas/desenvolvidas e os problemas da sociedade brasileira;

- estruturação e fortalecimento de uma carreira docente que reforça uma atuação voltada para a publicação de papers (preferencialmente no exterior) e para o ensino de pósgraduação; e

- estruturação administrativa da universidade (reforma universitária - Lei 5.540) segundo áreas e subáreas do conhecimento.

Esse quadro parece estar se revertendo, ou seja, a universidade passa por uma Segunda Revolução Acadêmica, quando assume uma terceira função como fundamental, na relação que estabelece com o setor produtivo. A tese da Segunda Revolução Acadêmica enfatiza que os trabalhos de consultoria sempre foram significativos em áreas como a química e a engenharia. O fenômeno novo é a participação ativa dos cientistas industriais nas instituições acadêmicas e nos centros ou institutos de pesquisa, e inversamente, os cientistas acadêmicos participarem no trabalho das empresas privadas (ETZKOWITZ e PETERS, 1991).

\subsection{O Triângulo de Sábato}

Com base em estudos prospectivos com o horizonte do ano 2000, Sábato e Botana (1968, p. 04) advogam que a região pode e deve participar no desenvolvimento científicotecnológico. A partir de sua compreensão acerca do processo político de desenvolvimento nas sociedades contemporâneas, recomendam como estratégia, para que essa participação 
fosse possível, "[...] a inserção da ciência e da tecnologia na própria trama do processo de desenvolvimento".

Apoiados em sua percepção do que demonstra a experiência histórica, esses autores (1968, p. 08) esclarecem resultar esse processo "[...] da ação múltipla e coordenada de três elementos fundamentais para o desenvolvimento das sociedades contemporâneas: o governo, a estrutura produtiva e a infraestrutura científico-tecnológica". Descrevem, ainda, graficamente essa relação: "Podemos imaginar que entre esses três elementos se estabelece um sistema de relações que se representaria pela figura geométrica de um triângulo, em que cada um deles ocuparia os vértices respectivos" (SÁBATO e BOTANA, 1968, p. 08). Assim, imaginando um triângulo apoiado em uma base, o governo ocupa o vértice superior, enquanto os outros dois elementos ocupam os vértices dessa base.

Sábato e Botana (1968) apresentaram três tipos de relações:

- intrarrelações: aquelas que ocorrem entre os componentes de cada vértice. Relações deste tipo permitiram, por exemplo, que os modestos laboratórios anteriores à Segunda Grande Guerra se transformassem em "fábricas de conhecimentos";

- inter-relações: aquelas que se estabelecem deliberadamente entre pares de vértices. Assim, podem ocorrer inter-relações verticais (entre vértice governo e cada um dos vértices da base do triângulo) e inter-relações horizontais (entre a infraestrutura científico-tecnológica e a estrutura produtiva;

- extrarrelações: as criadas entre uma sociedade (na qual funciona o triângulo de relações) e o exterior. Manifestam-se, por exemplo, no intercâmbio científico, no comércio externo de tecnologia e na adaptação de tecnologias importadas.

As inter-relações afiguram-se como as mais interessantes a serem exploradas. Em primeiro lugar, porque evidenciam o fato de ser o esforço de aprimoramento das interrelações, ainda que necessário, condição insuficiente para o desenvolvimento da sociedade. Em outras palavras, não basta, por exemplo, aumentar os recursos destinados à $\mathrm{P} \& \mathrm{D}$ - Pesquisa e Desenvolvimento - nas universidades e nos institutos de pesquisa. Em segundo, porque chamam a atenção da necessidade de uma sociedade ter articulado o seu triângulo integrado, para possuir capacidade de criação e de resposta frente a outros triângulos externos.

Constata-se que há mais de um quarto de século já havia sido estabelecida a necessidade básica de articular a universidade e a empresa, como também reconhecida a dificuldade em forjar essa articulação.

No Brasil, algumas ações nessa direção podem ser relacionadas, mostrando atitudes pró-ativas do governo na promoção da interação. Embora requeiram alguns ajustes, essas ações não deixam de representar uma mudança significativa no papel de espectador da interação universidade-empresa.

\subsection{Contextualização histórica da relação universidade-empresa (U-E)}

Frente às inovações tecnológicas e à complexidade mercadológica, as pesquisas em Ciência e Tecnologia (C\&T) se tornaram relevantes no cenário mundial, acentuando sua necessidade e importância para a geração de riqueza e a melhoria da qualidade de vida de regiões e países.

A relação universidade-empresa passou a apresentar laços estreitos, especialmente nos Estados Unidos e na Europa, durante a Segunda Guerra Mundial, quando pesquisas de cunho armamentista eram financiadas por diversas fundações. Posteriormente foram criados, nos Estados Unidos, programas e institutos governamentais de incentivo à pesquisa, como 
o Massachusets Institute of Tecnology (MIT), dando prioridade aos setores de interesse dos governos dos Estados, que também investiam nas universidades.

Essa cooperação U-E se firma no final do século XIX e início do século XX, quando as universidades "deixaram de se preocupar apenas com a preservação da cultura e a transmissão de saberes, e passaram a trabalhar com pesquisas para produzir 'conhecimentos em campos especiais' (VELHO, 1996 apud MAIA, 2005, p. 91). Webster e Etzkowitz (1991), por sua vez, apontam como a Segunda Revolução Acadêmica esse momento, quando a universidade assume uma relação com o setor produtivo.

A relação universidade-empresa se estreita com a adoção do modelo alemão, ou seja, ótica científico-profissional, por algumas universidades norte-americanas, como Princeton, Michigan, Harvard e Stanford.

Durante a crise do fordismo nos anos 1970, ocorre uma maior integração universidadeempresa, devido à redução dos recursos voltados à pesquisa nas universidades tanto dos Estados Unidos quanto da Europa. A partir dessa década, como ressalta Velho (1996), essa conexão passa a ser mais formal, organizada e incentivada, havendo injeção de recursos do setor privado e políticas governamentais. Assim, consolida-se a busca de cooperação como fator de competitividade.

No Brasil, para se demonstrar ou sumarizar as principais tendências, pode-se dividir o ensino superior em três períodos.

Na primeira Republica, o ensino superior estava voltado a formar bacharéis e alguns poucos profissionais liberais nas áreas de Direito, de Medicina e de Engenharia, pois necessitavase atender às classes dominantes.

Com a revolução de 1930, por meio do processo de urbanização e industrialização, exigiu-se que a universidade provocasse mudanças em sua estrutura para atender aos interesses industriais do Estado. Nessa época, os investimentos passaram a atender ao setor urbano, e não mais aos rurais.

Por meio da reforma Francisco Campos, em 1931, instaurou-se um modelo único de universidade para todo o país, que defendia a tese de que a universidade deveria manter o espírito científico. Porém, o País necessitava formar técnicos dos outros níveis de ensino e, então, foram reduzidas as atividades de pesquisa e experimentos técnicos, colocando a pesquisa em segundo plano.

O marco importante na década de 1930 foi a criação da Universidade de São Paulo (USP) em 1934, que tinha como propósito a pesquisa desinteressada e os estudos superiores de alto nível. A USP buscava um modelo segundo o qual a pesquisa estaria identificada com a ciência, e não exclusivamente com a tecnologia. Foi, portanto, implantado, no Brasil, o modelo europeu, com seu quadro de docentes da época formado por professores da França, que acreditavam que a universidade não deveria custear pesquisas com recursos privados, e sim do Estado.

Com essa proposta, a ciência não conseguiu ocupar um espaço relevante no cenário nacional, mas pode-se afirmar que os pesquisadores da época já objetivavam o desenvolvimento econômico do país.

Com o intuito de proteger os cientistas e suas condições de trabalho, além de concretizar a importância da ciência no Brasil, foi criada a Sociedade Brasileira para o Progresso da Ciência (SBPC). O discurso da SBPC era no sentido de que a ciência deveria ser o determinante do desenvolvimento econômico, porém, os cientistas é que deveriam preocupar-se em definir se as pesquisas desenvolvidas teriam apenas o direcionamento ao setor industrial. 
Diversos autores veem com reserva o incentivo à cooperação universidade-empresa. Durhan (1991, p. 14) enfatiza que a aproximação com o setor produtivo consiste na absorção, por parte da uUniversidade, de uma nova função, que não pode, e nem deve, transformar-se na função central da universidade, prejudicando sua vocação tradicional, que inclui o ensino e a pesquisa pura.

Na concepção de Chauí (1995, p. 58), o que está sendo chamado de modernização, na verdade, é a criação da "universidade de serviços", baseada na docência e pesquisa "de resultados", trazendo de volta uma das mais antigas concepções do que, outrora, chamavase "trabalho servil", isto é, uma atividade que tem como figura determinante o usuário que encomendou o serviço, enquanto a ação produtora propriamente dita é considerada apenas a executante de uma rotina adquirida, cuja finalidade e sentido lhe escapam.

Para Silva (1995, p. 67), do ponto de vista das relações universidade-empresa, não seria, portanto, adequado pensar que as necessidades das organizações empresariais devessem atuar como condicionantes externos à pesquisa universitária, mesmo considerando que tais necessidades se insiram no conjunto mais amplo das necessidades sociais às quais a universidade deveria atender. A coerência obriga a optar, segundo o autor, pela autodeterminação da atividade universitária como a melhor forma de satisfazer às necessidades sociais, de acordo com as mediações específicas às quais deve obedecer ao trabalho universitário.

$\mathrm{Na}$ mesma época, foi criado o Conselho Nacional de Desenvolvimento Científico e Tecnológico $(\mathrm{CNPq})$ e a Coordenação de Aperfeiçoamento de Pessoal de Nível Superior (CAPES), "Órgãos" vinculados ao governo federal para investir na capacitação dos recursos humanos, tanto no Brasil, como no exterior. Além disso, empresas estatais passaram a demandar e a investir em pesquisas.

Nos anos 1960, foi criada a Universidade de Brasília (UnB), visando a reforçar a relação universidade-empresa (U-E), e que representaria, efetivamente, um novo modelo de universidade. Cunha (1983, p. 12) aponta que a modernização do ensino superior empreendida pela reforma universitária destinava-se a colocar a universidade a serviço da produção prioritária de uma nova força de trabalho, requisitada pelo capital monopolista, organizado nas formas estatal e privada-multinacional.

Em 1985, é criado o Ministério da Ciência e Tecnologia (MCT), além de um incentivo fiscal para as empresas que investissem em Pesquisa e Desenvolvimento (P\&D).

Na década de 1990, ocorre a abertura do mercado com os governos Fernando Collor de Mello e Itamar Franco (1992-1995). Com isso, as empresas nacionais passam a concentrar seus esforços no aspecto produtividade, para reduzir custos e aumentar a qualidade, e se compararem aos concorrentes estrangeiros, além de buscarem novas tecnologias e novos modelos de gestão. A cooperação, porém, ainda não é atingida.

\subsection{Estruturação dos cursos superiores de tecnologia}

Conforme Resolução CNE/CP3/2002, a estruturação dos cursos superiores de tecnologia deve garantir aos cidadãos o direito à aquisição de competências profissionais que os tornem aptos para a inserção em setores profissionais, nos quais haja utilização de tecnologias, além de conter, na essência de sua proposta acadêmica, características próprias que os especifiquem, conforme Artigo 2 o da Resolução CNE/CP3/2002:

I - incentivar ao desenvolvimento da capacidade empreendedora e da compreensão do processo tecnológico, em suas causas e efeitos;

Rev. Adm. UFSM, Santa Maria, v. 2, n. 3, p. 479-498, set./dez. 2009 


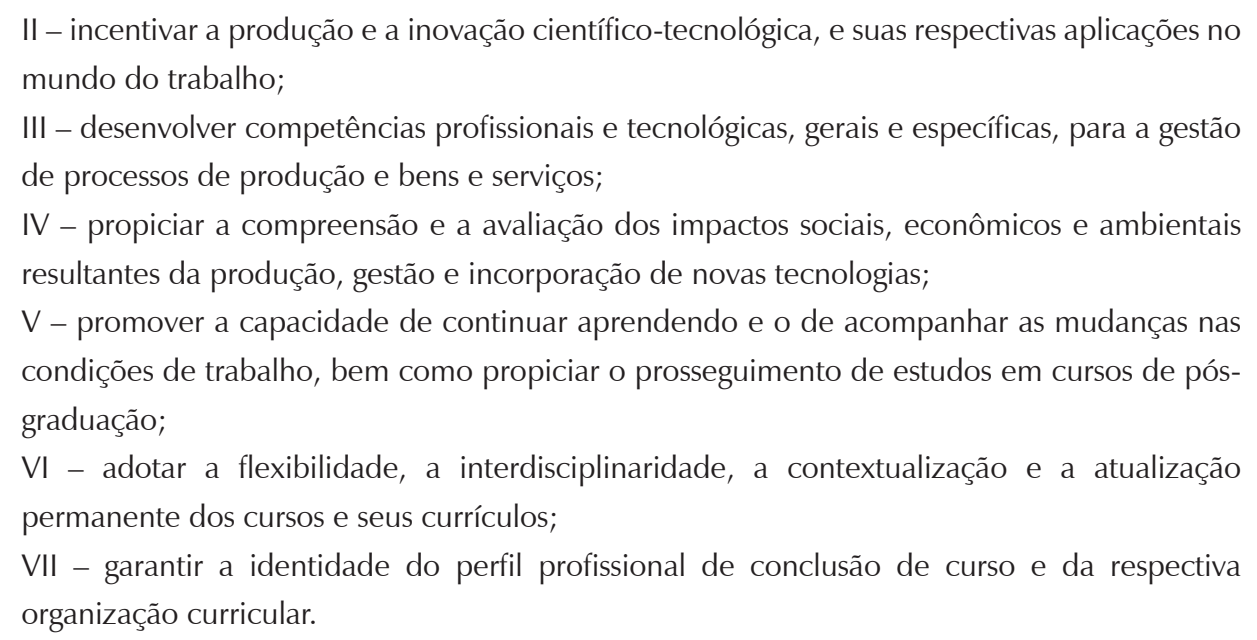

Seguindo a estruturação dos cursos superiores de tecnologia, atualmente os cursos ministrados pelo Centro Estadual de Educação Tecnológica Paula Souza obedecem ao disposto na Lei n. 9.394, de 20 de dezembro de 1996; do Decreto Federal 2.208, de 17 de abril de 1997; do parecer CNECES n. 436, de 02 de abril de 2002; da Resolução CNE/CP3, de 18 de dezembro, e das demais normas específicas, expedidas pelos órgãos competentes (BRASIL, 2002). E segue, ainda, um modelo de estruturação sistêmica que otimiza, metodologicamente, os projetos pedagógicos dos cursos superiores de tecnologia.

A formação básica é obrigatória para todos os cursos superiores de tecnologia. Compõe-se das disciplinas básicas e dos conceitos metodológicos indispensáveis à formação integral de um profissional competente e criativo, capaz de compreender seus ambientes, tanto de atuação, como de vida. Oferece o instrumental metodológico adequado para o processo de "aprender a aprender" e o de "aprender a ser", caracterizando-se pelo conjunto de conhecimentos fundamentais, de caráter geral, comportamental, científico, tecnológico e metodológico.

A história do ensino profissionalizante no Brasil, foi marcada por decretos e portarias, baixados pelo poder central, na tentativa permanente de compatibilizar esse ensino com as variações do mercado, da sociedade e da produção.

\subsection{Definição de micro e pequena empresa}

Definir o que seja micro e pequena empresa envolve um grau relativo de dificuldade, conforme apontam diversos autores, uma vez que devem ser considerados fatores quantitativos e distintas realidades econômicas, nacionais e regionais.

Segundo Leone (1991), a classificação do tamanho das empresas, incluindo-se as micro e pequenas empresas, apresenta determinada dificuldade, tanto para a academia, em seus estudos, quanto para a esfera governamental na implantação de qualquer política de apoio ao fomento nessa área. Dessa forma, encontra-se uma grande variação nos critérios para classificar micro e pequena empresa. Muitas fontes adotam apenas o conceito de microempresa; outras, trabalham com as categorias pequena e média empresa, tradicionalmente, utilizando variáveis como mão de obra empregada, capital investido, faturamento, quantidade produzida. O conceito do governo brasileiro é respaldado por legislações específicas a tais empresas, na tentativa de assegurar-lhes tratamento jurídico diferenciado e simplificado nos campos administrativo, 
tributário, previdenciário, trabalhista, creditício e de desenvolvimento empresarial, de acordo com o artigo primeiro da Lei 9.841, de 05/10/1999 (artigos170 a 179 da constituição federal), além da recente Lei Complementar 123/06.

De acordo com o Decreto 5.028, de 31 de março de 2004, o critério adotado para conceituar micro e pequena empresa é a receita bruta anual, cujos valores variam: de até $R \$$ $433.755,14$ anuais para microempresa; de $\mathrm{R} \$ 433.755,14$ até $\mathrm{R} \$ 2.144 .222,00$ anuais, para pequena empresa.

O Serviço Brasileiro de Apoio às Micro e Pequenas Empresas (SEBRAE) apresenta uma classificação de empresas por porte, seguindo uma orientação do Instituto Brasileiro de Geografia e Estatística (IBGE), e que tem sido utilizada por essa instituição em todo território nacional. A classificação é feita por setor de atividade, ou seja, na indústria, a microempresa possui até 19 empregados, a pequena de 20-99, e a média de 100-499 empregados. No setor comércio/serviços, a microempresa possui até 9 empregados, a pequena de 10-49, e a média de 50-99 empregados conforme tabela 1.

Tabela 1 - Classificação das empresas

\begin{tabular}{l|l|l|l|l}
\multicolumn{1}{c|}{ Setor } & \multicolumn{1}{c|}{ Micro } & \multicolumn{1}{c|}{ Pequena } & \multicolumn{1}{c}{ Média } & \multicolumn{1}{c}{ Grande } \\
\hline Indústria & Até 19 & De 20 a 99 & De 100 a 499 & Acima de 500 \\
\hline Comércio & Até 09 & De 10 a 49 & De 50 a 99 & Acima de 100 \\
\hline Serviços & Até 09 & De 10 a 49 & De 50 a 99 & Acima de 500 \\
\hline
\end{tabular}

Fonte: SEBRAE (2008).

\subsection{C contexto econômico e social da micro e pequena empresa}

A partir dos anos 1970 as pequenas empresas passaram a ocupar espaços crescentes em variados setores de atividade. Bannock (1981), Audretsch (1995) e Hull e Hjern (1987), citando estudo do MIT, coordenado por David Birch, mostram que 66\% dos novos empregos líquidos, criados pelas firmas nos Estados Unidos entre 1969 e 1976, foram de responsabilidade de empresas com menos de 20 empregados, e que as firmas com menos de cinco anos, à época de realização do estudo, concentravam mais de $80 \%$ do total dos empregos.

Drucker (1996) afirma que os "velhos criadores de emprego" estão perdendo empregos desde o final dos anos 1960, e que a criação e o crescimento dos empregos nos Estados Unidos estão ocorrendo em um "novo setor", o das pequenas empresas. Trata-se de um processo caracterizado pelo autor como de "profunda mudança, de uma economia 'gerencial' para uma economia empreendedora".

O resultado desse processo é que as pequenas empresas passaram a representar a esmagadora maioria das unidades de negócio em todos os países industrializados, em desenvolvimento ou subdesenvolvidos. Passaram também a responder por cerca de 50\%, quando não mais, do valor da produção, além de reterem mais da metade do total dos postos de trabalho.

O Brasil, no que diz respeito às micro e pequenas empresas, está entre os primeiros países na atividade empreendedora pela quantidade de empresas abertas a cada ano (PRADO, 2001). Muitos estudos têm sido desenvolvidos enfocando as variadas características que essas 
empresas apresentam, tais como a taxa de mortalidade, a estrutura e o processo decisório, as dificuldades de gestão e a identificação de problemas.

Em todos os setores de atividades desenvolvidas no país, as micro e pequenas empresas estão presentes, representando um expressivo aumento nos postos de ocupação para toda a população brasileira (AZOLINI, 2001)

Ainda para o Sebrae (1999), a participação econômica da pequena empresa no Brasil é de $43 \%$ no total de empregos e $98,23 \%$ no total de empresas. Portanto, as micro e pequenas empresas são setores estratégicos da economia do país e representam fatores-chave para a criação de empregos, para a melhoria da distribuição de rendas e para o desenvolvimento da sociedade. Além do papel social na geração de empregos, a pequena empresa desempenha importante e particular função econômica, resultante de duas de suas características: seu potencial empreendedor e seu desenvolvimento.

Kirchhoff (1988) ressalta que a visão do surgimento de novos negócios e do crescimento econômico, com base na pequena empresa, tem fundamento na teoria schumpeteriana da "destruição criadora", segundo a qual a força do capitalismo está baseada não na condição estática de um setor econômico, mas na dinâmica de empreendedores "destruindo criativamente" a estrutura econômica existente.

O outro fator que explica fortemente o desenvolvimento dessas empresas é a sua capacidade de inovar e incorporar inovações. Esses dois atributos não se têm mostrado, no entanto, suficientes para assegurar a sobrevivência do expressivo número de novas empresas. Isso coloca, pois, o desafio de se encontrar ou construir mecanismos, especialmente os institucionais, que possam contribuir para o fortalecimento dessas empresas.

\subsection{Causas da mortalidade das MPEs}

Muito se tem discutido e escrito sobre a importância dos pequenos negócios para o desenvolvimento socioeconômico. Da literatura (DEAKINS, 1996); (BATALHA E DEMORI, 1990); (PASSOS, 1996); (NAISBITT, 1994); (KRUGLIANSKAS, 1996 apud LEZANA e LIMA, 2000); podem ser extraídos alguns argumentos centrais, como a grande capacidade de absorção de mão de obra menos qualificada, a integração às grandes cadeias produtivas, que se prestam ao papel de instrumentos da descentralização econômica e democratização do capital, o que as torna mais flexíveis nas operações, e mais ágeis no processo decisório.

O Serviço de Apoio às Micro e Pequenas Empresas Paulistas (SEBRAE-SP), indica que $27 \%$ das empresas fecham no primeiro ano; $38 \%$ encerram suas atividades até o segundo ano; $46 \%$ fecham antes do terceiro ano; $50 \%$ não concluem o quarto ano; $62 \%$ fecham até o quinto ano; e, 64\% encerram suas atividades antes de completarem seis anos de atividade (ver Gráfico $1)$.

Nos últimos dez anos, o SEBRAE-SP realizou cinco pesquisas sobre mortalidade de empresas, que envolveram o rastreamento pessoal dos sócios proprietários e entrevistas. O Gráfico 2 apresenta os resultados dos cinco estudos realizados, e permite fazer uma avaliação da evolução comparativa das taxas de mortalidade nos últimos dez anos. Os dados evidenciam uma tendência à queda das taxas de mortalidade ao longo do tempo, para empresas com um, dois, três, quatro anos de atividade. Com relação às empresas com até um ano de atividade, a taxa de mortalidade cai de 35\% no primeiro estudo (1998/1999), para 27\% no último estudo (2006/2007).

Embora seja visível a tendência de queda da taxa de mortalidade, no conjunto dos estudos, especificamente para empresas de até cinco anos, essa tendência parece ter sido 
revertida no último rastreamento. A taxa de mortalidade de empresas de até cinco anos caiu de $71 \%$ no estudo de $2000 / 2001$ para $56 \%$ no estudo de $2004 / 2005$, e voltou a crescer para $62 \%$ no estudo de 2006/2007.

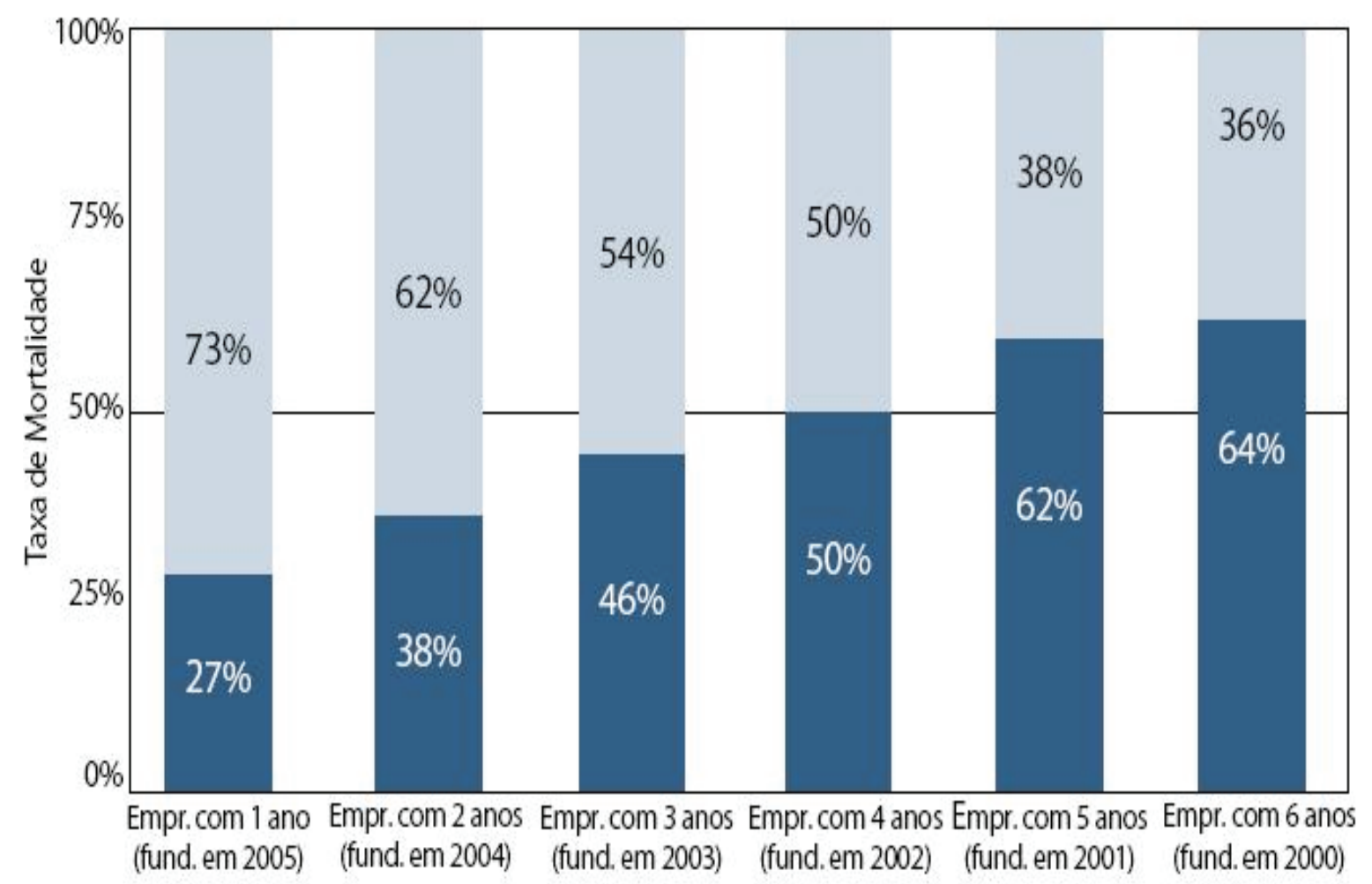

empresas encerradas empresas em atividade

Fonte: Observatório das MPEs do Sebrae-SP (2008).

Gráfico 1 - Sobrevivência e mortalidade acumulada das empresas, Estado de São Paulo. 

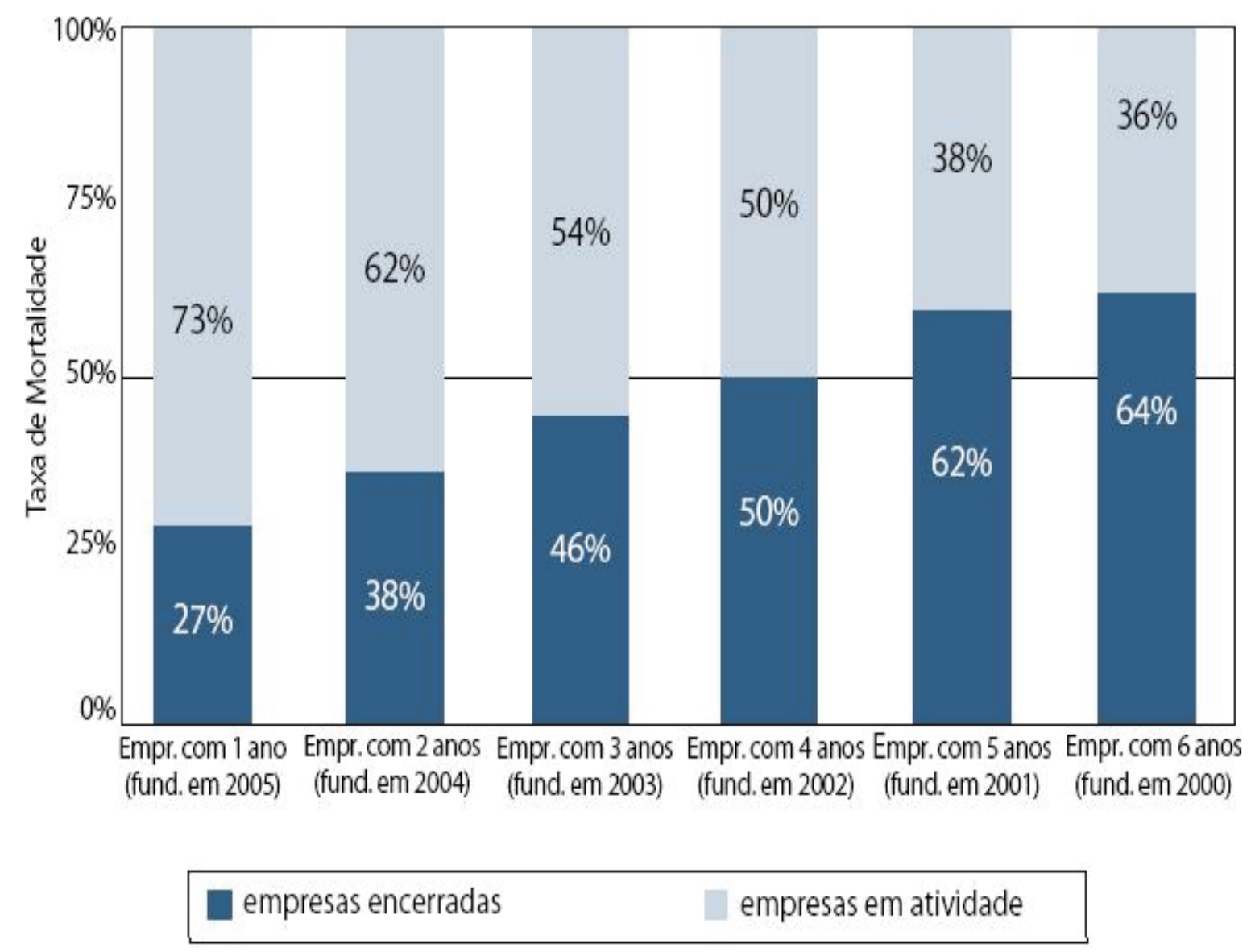

Fonte: Observatório das MPEs do Sebrae-SP - 2008

Gráfico 2 - Comparação de taxas: estudos anteriores vs estudo atual.

O conjunto de fatores econômicos e sociais que contribuíram para a melhoria em termos de sobrevivência de empresas inclui os seguintes itens:

a) melhorou o ambiente dos negócios: houve redução das taxas de juros, ampliação da oferta de crédito, manutenção da inflação sob controle, adoção de novas leis (Simples Federal, Simples Estaduais, Estatuto, Lei Geral das Micro e Pequenas Empresas);

b) melhorou o perfil dos empresários: proporcionado pelo aumento da escolaridade, aumento na procura por auxilio nas entidades de apoio às empresas, aumento na participação dos empresários em reuniões de entidades e em ações conjunta com outras empresas;

c) melhorou o perfil das empresas: diminuiu a proporção de novas empresas no setor de comércio, ampliou a proporção de empresas do tipo "sociedade" vis-à-vis, as empresas "individuais", aumentou a proporção de empresas que vendem aos governos federal, estadual e municipal;

d) melhorou o planejamento prévio (mas não a gestão empresarial): aumento no tempo médio de planejamento das empresas, antes de sua abertura. 


\subsection{A importância da cooperação universidade-empresa para ambas as instituições}

O debate sobre a interação da universidade com o setor produtivo remonta ao início do século XX, contudo o interesse por essa interação ganhou força no final da década de 1970 nos países centrais e, uma década mais tarde, nos periféricos.

Segundo Segatto-Mendes e Sbragia (2002), as relações promovidas pela integração universidade-empresa não significam apenas um relacionamento; englobam também um processo de transferência e transformação de produtos e serviços.

Para que aconteça o processo de cooperação universidade-empresa, é necessário que se entenda tal processo essencialmente como uma relação de troca, de comprometimento, de parceria entre a instituição de ensino e a empresa (Figura 1).

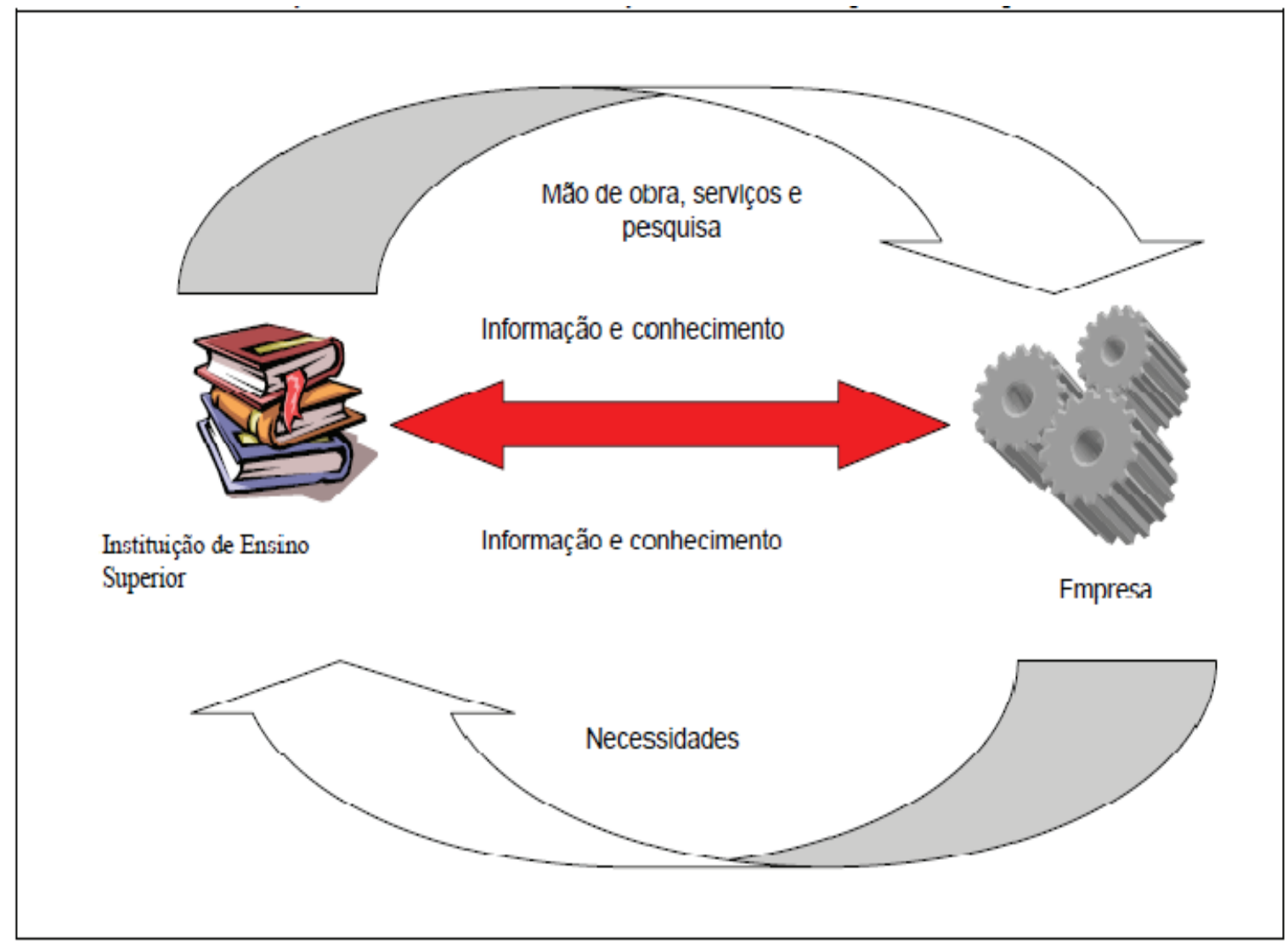

Fonte: Adaptado pelo autor de Alessio (2004, p. 101).

Figura 1 - Relação de troca entre instituição de ensino superior e empresa.

\subsection{Mecanismos de cooperação universidade-empresa}

Para viabilizar as modalidades e/ou mecanismos de interação entre a universidade e o setor produtivo, há a necessidade de organização desse processo, mediante a criação de modelos e/ou mecanismos.

Alguns aspectos devem ser observados e analisados para fortalecer o processo de interação entre a universidade e a empresa, como, por exemplo, é necessário conhecer o 
ambiente no qual as interações acontecem, para que as mesmas possam ser fortalecidas:

- ambiente interno: constituído pelos cursos, departamentos acadêmicos, grupos de pesquisas, laboratórios e pelo público interno - a administração da instituição, os funcionários ou servidores, os professores, os estudantes, os colegiados internos (conselhos diretores ou universitários);

- ambiente externo: empresas, outras IES, órgãos governamentais, associações de profissionais, associações comerciais e industriais e o público externo - profissionais que atuam nessas instituições e a população local;

- macroambiente: as forças políticas, econômicas, sociais, ecológicas e demográficas que afetam a instituição. Kotlher e Fox (1994) destacam dois atributos do macroambiente: a permanente mutação e as forças macroambientais que estão fora de controle e de influência das instituições educacionais ou de qualquer outra organização ou grupo de organizações.

Zagottis (1995, p. 82) relaciona sete mecanismos clássicos de interação universidadeempresa. Um primeiro mecanismo, constituído pelos próprios cursos de graduação, tornase mais forte e evidente quando estes possuem uma organização cooperativa, com períodos letivos alternados com estágios supervisionados realizados no setor produtivo.

Um segundo mecanismo de interação é constituído pelos cursos de pós-graduação, cuja finalidade é formar mestres e doutores que atuem como professores, consultores e pesquisadores de alto nível, tanto para as instituições de ensino e pesquisa, quanto para os centros empresariais de pesquisa e desenvolvimento.

Um terceiro mecanismo de interação, mais diretamente vinculado aos interesses do setor produtivo, é constituído pelos cursos de educação continuada (atualização e especialização). Tais cursos têm a característica de permitir um primeiro contato próximo entre os docentes e os membros do corpo técnico do setor produtivo, o que é importante para o estabelecimento da confiança recíproca e de avaliações de competência.

Um quarto mecanismo de interação é constituído pelas atividades de consultoria científica e tecnológica prestadas diretamente pelo corpo docente ao setor produtivo, consistindo tal mecanismo num dos mais difundidos e efetivos, inclusive porque os principais projetos institucionais de pesquisa quase sempre decorrem de atividades prévias de consultoria.

Como quinto mecanismo de interação, têm-se os contratos institucionais de pesquisa e desenvolvimento, que representam o mais importante de todos os mecanismos, tanto para a universidade, como para o setor produtivo. Um problema complexo apresentado é o da sua adequada gestão por parte da universidade, que precisa associar a excelência científica e tecnológica às questões pragmáticas dos custos e dos prazos.

As incubadoras de empresas nascentes, especialmente as de alta tecnologia, constituem um sexto mecanismo de interação. A importância crescente das micro e pequenas empresas na economia, tanto em termos de oferecimento de empregos, quanto em termos de introdução de inovações, torna altamente desejável a sua proliferação.

Finalmente, uma sétima forma de interação, diz respeito aos parques tecnológicos, construídos, quase sempre, em torno de universidades de alto nível de excelência, seguindo o modelo da Universidade de Stanford, que gerou o Vale do Silício.

Bonaccorsi e Piccaluga (1994) apresentam formas de cooperação universidadeempresas divididas em seis categorias, conforme pode-se verificar no Quadro 1. 


\begin{tabular}{|c|c|c|c|}
\hline & Tipos de Relação & Descrição & Exemplos \\
\hline $\mathrm{I}$ & $\begin{array}{l}\text { Relações Pessoais } \\
\text { Informais (a } \\
\text { universidade não é } \\
\text { envolvida) }\end{array}$ & $\begin{array}{l}\text { Ocorrem quando a empresa e } \\
\text { uma pessoa da universidade } \\
\text { efetuam trocas, sem que } \\
\text { qualquer acordo formal, que } \\
\text { envolva a universidade, seja } \\
\text { elaborado }\end{array}$ & $\begin{array}{l}\text { Consultoria individual por acadêmicos, } \\
\text { workshops informais, reuniões para troca } \\
\text { de informações, publicações de resultados } \\
\text { de pesquisa }\end{array}$ \\
\hline II & $\begin{array}{c}\text { Relações Pessoais } \\
\text { Formais (convênios } \\
\text { entre universidade e } \\
\text { empresa) }\end{array}$ & $\begin{array}{l}\text { São como as relações pessoais } \\
\text { informais só que com a } \\
\text { existência de acordos } \\
\text { formalizados entre a U-E }\end{array}$ & $\begin{array}{l}\text { Bolsas de estudo e apoio à pós-graduação, } \\
\text { estágios de alunos, intercâmbio de } \\
\text { pessoal, especialização de funcionários } \\
\text { nas universidades. }\end{array}$ \\
\hline III & $\begin{array}{l}\text { Envolvimento de uma } \\
\text { Instituição de } \\
\text { Intermediação }\end{array}$ & $\begin{array}{l}\text { Surge um grupo intermediário. } \\
\text { Estas associações, que } \\
\text { intermediarão as relações } \\
\text { podem estar dentro da } \\
\text { universidade, serem } \\
\text { completamente externas, ou } \\
\text { ainda estarem em uma posição } \\
\text { intermediária. }\end{array}$ & $\begin{array}{l}\text { Relação de parceria via terceiros sob a } \\
\text { forma de associações industriais, institutos } \\
\text { de pesquisa aplicada, escritórios de } \\
\text { assistência geral, consultoria institucional } \\
\text { (companhias/fundações universitárias) }\end{array}$ \\
\hline IV & $\begin{array}{l}\text { Convênios Formais } \\
\text { com Objetivo Definido }\end{array}$ & $\begin{array}{l}\text { Relações em que ocorre tanto } \\
\text { a formalização do acordo, } \\
\text { como também a definição dos } \\
\text { objetivos específicos de } \\
\text { colaboração desde o início. }\end{array}$ & $\begin{array}{l}\text { Pesquisa contratada, desenvolvimento de } \\
\text { protótipos e teses, treinamento de } \\
\text { funcionários, projetos de pesquisa } \\
\text { cooperativa ou programa de pesquisa } \\
\text { conjunto. }\end{array}$ \\
\hline $\mathrm{V}$ & $\begin{array}{l}\text { Convênios Formais } \\
\text { sem Objetivos } \\
\text { Definido (tipo "guarda- } \\
\text { chuva") }\end{array}$ & $\begin{array}{l}\text { Acordos formalizados, como } \\
\text { no caso anterior, mas cujas } \\
\text { relações possuem maior } \\
\text { quantidade de objetivos } \\
\text { estratégicos e de longo prazo. }\end{array}$ & $\begin{array}{l}\text { Patrocínio industrial de pesquisa e } \\
\text { desenvolvimento em departamentos da } \\
\text { universidade, doações e auxílios para } \\
\text { pesquisa, genéricos ou para departamentos } \\
\text { específicos. }\end{array}$ \\
\hline VI & $\begin{array}{l}\text { Criação de Estruturas } \\
\text { Próprias para a } \\
\text { Interação }\end{array}$ & $\begin{array}{l}\text { São as iniciativas de pesquisa } \\
\text { conjuntamenter conduzidas } \\
\text { pela industria e a universidade } \\
\text { em estruturas permanentes } \\
\text { específicas }\end{array}$ & $\begin{array}{l}\text { Parques tecnológicos, institutos, } \\
\text { laboratórios, incubadoras de empresa, } \\
\text { consórcios de pesquisa. }\end{array}$ \\
\hline
\end{tabular}

Fonte: Adaptado de Bonaccorsi e Piccaluga (1994).

Quadro 1 - Modalidades de relacionamento entre universidade e empresa.

Ripper Filho (1994, p. 150) apresenta a criação de empresas por pesquisadores universitários como um dos mais eficientes mecanismos de transferência de conhecimentos e geração de interações estáveis. Segundo o autor, um pesquisador universitário que se tornou empresário é uma pessoa com conhecimento das duas culturas. Esse pesquisador/empresário, naturalmente, percebe a importância da interação e saberá como enfrentar as dificuldades para efetivá-la, reduzindo o risco individual envolvido, com licenças por até três anos, por exemplo. A universidade ganha em qualquer hipótese, avalia o autor; e, se o pesquisador retornar, sua experiência o tornará de grande valia para a universidade; se não retornar, naturalmente manterá a interação.

Carvalho (2000), em seu estudo, intitulado Inteligência Competitiva Tecnológica para Pequenas e Médias Empresas através da Cooperação Escola-Empresa, apresenta, de forma mais explícita, oito arranjos para as atividades de interação:

- assistência direta com gestão descentralizada: contatos diretamente realizados entre o setor demandante da atividade na empresa e o setor da instituição de ensino;

- assistência direta com gestão centralizada: neste caso, as demandas são centralizadas em um órgão gestor da empresa e um da instituição de ensino, que controlam todo o processo do começo ao fim; 
- assistência direta com gestão monitorada: esse modelo permite e estimula que os grupos mantenham contatos e que entabulem atividades de cooperação. "Os órgãos gestores funcionam como apoio administrativo e gerencial. Vantagem: autonomia dos grupos. Desvantagem: entendimento parcial e superficial das atividades desenvolvidas";

- via órgãos de interface: neste arranjo o órgão de interface é externo à estrutura organizacional, tanto da empresa, como a instituição de ensino. Tem como objetivo principal a empresa e a busca de financiamentos externos. Para Carvalho (2000), a característica principal do Centro de P\&D está em possuir um pessoal próprio para pesquisar e/ou desenvolver tecnologias. Esse pessoal próprio pertence aos grupos/setores da empresa e da instituição de ensino e estão, normalmente, alocados em equipes de projeto dentro do centro. O órgão gestor pode, se julgar necessário, estabelecer algum tipo de acompanhamento. Vantagem: autonomia. Desvantagem: distância física do ambiente de ensino;

- via laboratório compartilhado: ocorre quando dentro da instituição de ensino, uma determinada empresa instala um laboratório, de um modo geral de pesquisa ou de testes, e cujo controle e utilização é compartilhado;

- multicliente cooperativa: a instituição de ensino superior desenvolve, neste modelo, um projeto que é de interesse de múltiplas empresas. As pessoas da empresa não interagem diretamente com o(s) grupo(s) de pesquisa;

- multicliente-consórcio: o autor destaca que o projeto pode ser subdividido e desenvolvido parcialmente em algum outro consorciado (empresa ou instituição de ensino), entretanto todo o monitoramento é centralizado. Aponta, ainda, como vantagem, a abrangência do modelo e, como desvantagem, a necessidade de uma alta capacidade gerencial;

- via centro de P\&D: nesse caso, o órgão gestor pode, se julgar necessário, estabelecer algum tipo de acompanhamento. Para Carvalho (2000), a vantagem consiste na autonomia que o Centro de P\&D possui, e a desvantagem é a distância física do ambiente de ensino.

Lima (2004) defende que os mecanismos de interação entre a universidade e as empresas sejam criados e desenvolvidos de maneira gradual, ou seja, em forma de estágios e visitas técnicas, evoluindo para interações de maior complexidade, chegando a ter, na universidade, a participação da sociedade na definição dos caminhos a serem seguidos.

Segundo Autio e Laamanen (1995), esses mecanismos podem ser classificados em três categorias:

- mecanismos de processos: serviços;

- mecanismos de processo: arranjos organizacionais;

- mecanismos de resultados: resultados de pesquisa.

A prestação de serviços tem sido vista positivamente quando permite às empresas o acesso a equipamentos caros ou não disponíveis no mercado.

Para Giuliani (1998), é necessário compreender as expectativas e as motivações que induzem as empresas e as universidades a se unirem para pesquisar, para um maior entendimento do processo como um todo, bem como dos benefícios que podem ser alcançados, o que justifica a expansão que essas relações vêm apresentando. 


\begin{tabular}{|c|c|}
\hline \multirow{13}{*}{$\begin{array}{c}\text { Mecanismos de } \\
\text { Cooperação } \\
\text { Universidade- } \\
\text { Empresa }\end{array}$} & Estágio Curricular \\
\hline & Prestação de serviços não rotineiros \\
\hline & Resolução de consulta de pequena complexidade \\
\hline & $\begin{array}{l}\text { Conselho Empresarial, formado por empresários e representantes da } \\
\text { sociedade organizada, como função consultiva }\end{array}$ \\
\hline & $\begin{array}{l}\text { Estágio de alunos e professores em empresas e instituições } \\
\text { congêneres no exterior }\end{array}$ \\
\hline & Pesquisas tecnológicas em parceria \\
\hline & Prestação de serviço de cunho tecnológico \\
\hline & Balcão de teses \\
\hline & Projeto de final de curso de graduação apoiado por empresa \\
\hline & $\begin{array}{l}\text { Compartilhamento de equipamentos, cedidos por empresas, nas } \\
\text { universidades }\end{array}$ \\
\hline & Encontro com ex-alunos \\
\hline & Hotel tecnológico \\
\hline & Incubadora tecnológica \\
\hline
\end{tabular}

Fonte: Adaptado de Lima (2004).

Quadro 2 - Exemplos de mecanismos de cooperação universidade-empresa.

\subsection{Dificuldades no processo de cooperação universidade-empresa}

Uma das dificuldades para o incremento nas relações é que os segmentos científico e empresarial, de modo geral, estão bastante dissociados, apresentando desconfianças mútuas, dificultando o equilíbrio entre demanda e oferta tecnológica. Por muito tempo os resultados da pesquisa científica foram negligenciados pelas empresas. Também os cientistas não se mostravam interessados em comercializá-los. A falta de motivação para tal intercâmbio resulta de diversos fatores: atraso na publicação dos resultados de pesquisa; perda de sigilo; possibilidade de negligência dos setores de ensino e pesquisa e, ainda, o receio de perda de autonomia da universidade (BAETA, 1999).

Segundo Beirão (1999, p. 48), as instituições de ensino superior e seus pesquisadores não têm o conhecimento das reais necessidades tecnológicas da indústria. A universidade tem apenas um conhecimento genérico, poucas vezes sabendo os reais problemas tecnológicos de cada empresa. Por outro lado, "a falta de pessoal qualificado na indústria torna-se um obstáculo quase intransponível à transferência de tecnologias e ao desenvolvimento tecnológico das empresas".

\section{Considerações finais}

Para Marcovitch (1999), há dois mitos a destruir: "O primeiro cultivado pelos empresários, de que o pesquisador acadêmico é um ser etéreo deslocado da realidade. $\mathrm{O}$ segundo, a corrente na área de pesquisa, de que o empresário despreza a ciência". A interação 
entre as instituições de ensino e empresas, com a finalidade de realização de projetos de pesquisa e desenvolvimento, de modo geral, é, ainda, incipiente no Brasil.

Pode-se concluir que as empresas e as universidades possuem culturas diferentes e, por conseguinte, missões distintas, porém o fato de atuarem em projetos de cooperação não implica em mudança da missão, mas sim o entendimento de que cada participante pode complementar o outro. A cooperação somente terá êxito se essas diferenças forem levadas em conta e houver a vontade de ambas somarem esforços (LIMA, 2004).

Essa cooperação certamente trará benefícios para ambas as partes. Para as universidades, segundo Maculan e Merino (1998), essa cooperação universidade-empresa representa uma oportunidade para diversificar as formas de valorização dos conhecimentos e competências acumuladas, adquirir novas competências e assumir um novo papel no crescimento econômico. Além disso, para Januário Netto (1998), o relacionamento com as empresas tem sido uma alternativa importante para as universidades na busca de recursos financeiros para o financiamento de bolsas de estudos, aquisição de equipamentos e material de consumo, montagem de laboratórios e formação de grupos de pesquisa multidisciplinares e, ainda, como fonte de informações e de aprendizado, indispensáveis para o aprimoramento e para a atualização do ensino e da pesquisa institucional.

Já para as empresas, segundo Januário Netto (1998), essas parcerias geram a formação de pessoal especializado, a incorporação de novas tecnologias aos produtos e processos, o compartilhamento dos custos e a complementação de sua capacidade de pesquisa e desenvolvimento.

Giuliani (1998) acredita que os benefícios estendem-se para o país como um todo, por meio de um setor industrial mais competitivo, pesquisa de melhor qualidade, setor acadêmico com estabilidade superior na execução de pesquisas maiores e mais rápidas, inovações tecnológicas e fortalecimento da economia nacional.

Finalmente, conclui-se que, no contexto atual de globalização e de desenvolvimento de tecnologias de alto nível, essa cooperação é de grande importância para o País como um todo e influenciará positivamente os avanços tecnológicos.

\section{Referências}

ALESSIO, P. A. Informação e conhecimento: um modelo de gestão para potencializar a inovação tecnológica e a cooperação universidadeempresa. 2004. Tese (Doutorado em Engenharia de Produção) - Programa de Pós-Graduação em Engenharia de Produção, Universidade Federal de Santa Catarina, Florianópolis, 2004.

AUDRETSCH, D.B. Innovation and industry evolution. Cambridge: The MIT, 1995.

AUTIO, E.; LAAMANEN, T. Measurement and evaluation of technology transfer: review of technology transfer mechanisms and indicators. International Jounal of Technology Management, v.10, n.7/8, p. 643-664,1995.

AZOLINI, J. M. Gerenciamento de micro e pequenas empresas. 2001, 46 p. Notas de Aula, Não publicado.

BAETA, A. M. C. Incubadoras de empresa de base tecnológica: ampliando as fronteiras do ensino e da pesquisa acadêmica. Universidade e indústria: perspectivas da UFMG, Belo Horizonte, p. 65-74, mar. 1999..

BANNOCK, G. The economics of small firms: return from the wilderness. Oxford: Basil Blackwell, 1981. 
BATALHA, M. O.; DEMORI, F. A pequena e média indústria em Santa Catarina. Florianópolis: Ed. da UFSC, 1990.

BEIRÃO, P. S. L. Geração e transferência de tecnologia: um problema de recursos humanos. Universidade e indústria: perspectivas da UFMG, Belo Horizonte, p. 45-54, mar. 1999.

BONACCORSI, A.; PICCALUGA, A. A theoretical framework for the evaluation of universityindustry relationships. R\&D Management, v. 24, n. 3, p. 229-247, 1994.

BRASIL. Resolução n. 3, de 23.12.2002, que instituiu as Diretrizes Curriculares Nacionais Gerais para a organização e o funcionamento dos cursos superiores de tecnológica. Brasília, 2002.

BRISOLLA, S. de N. Universidade/empresas: os problemas de um relacionamento. Revista Educação e Sociedade, São Paulo, ano 13, n. 14, p.101-116, abr. 1992.

CARVALHO, H. G. de. Inteligência competitiva tecnológica para PME através da cooperação escola-empresa. 2000. Tese (Doutorado em Engenharia de Produção) - Programa de Pós-graduação em Engenharia de Produção - Universidade Federal de Santa Catarina, Florianópolis, 2000.

CRUZ, C. H. de B. A universidade, a empresa e a pesquisa que o país precisa. Revista Humanidades, Brasília: UNB, 2000.

CUNHA, L. A. A universidade temporã. 2. ed. Rio de Janeiro: Civilização Brasileira, 1980.

CHAUÍ, M. Em torno da universidade de resultados e de serviços. Revista USP, São Paulo, n. 25, p.54-61, mar./maio 1995.

DEAKINS, D. Entrepreneurship and small firms. Berkshire: Mc Graw-hill, 1996.

DRUCKER, P. F. Inovação e espírito empreendedor (entrepreneurship): prática e princípios. São Paulo: Pioneira, 1987.

DURHAN, E. R. A relação da universidade com o setor produtivo. Conferência apresentada. 1991.
ETZKOWITZ, H.; PETERS, L.S. Profiting from knowledge: organizational innovations and the normative changes in american universities. Minerva, São Carlos: RiMA/FIPAI, v.29, n.2, p. 133-166, 1991.

GIULIANI, A. C. Ensino profissional a relação universidade-empresa. Cadernos do CRH (UFBA), Piracicaba, SP, v. 5, n. 1, p. 89-97, 1998.

HULL, C. J.; HJERN, B. Helping small firms

grow: an implementation approach. New South Wales: Croom Helm, 1987.

JANUÁRIO NETTO, Eden. Interação escolaempresa. Revista Educação \& Tecnologia, Belo Horizonte: CEFET, ano 2., n. 3, Editorial, p. 1315, ago. 1998.

KIRCHHOFF, B. A. A multi-sector approach to small business policy development. In: JUDD, Richard J.; GREENWOOD, William T.; BECKER, Fred W. (Ed.). Small business in a regulated economy: issues and policy implications. Connecticut: Quorum Books, 1988.

KOTLHER, P.; FOX, K. F. A. Marketing estratégico para instituições educacionais. São Paulo: Atlas, 1994.

KRUGLIANSKAS, I. Tornando a pequena e média empresa competitiva. São Paulo: IEGE, 1996.

LEONE, N. M. de C. P. G. As especificidades das pequenas e médias empresas. Revista de Administração da USP-RAUSP, São Paulo, v. 34, n. 2, p.91-94, abr./jun. 1999.

LEZANA, A.G.R.; LIMA, A.F.T.F.C.

comportamento empreendedor: uma nova perspectiva para diagnóstico organizacional em pequenos negócios. In: ENCONTRO NACIONAL DE EMPREENDEDORISMO, 2., Florianópolis, 2000. Anais... Florianópolis: UFSC, 2000.

LIMA, I.A. Estrutura de referência para a transferência de tecnologia no âmbito da cooperação universidade-empresa. 2004. Tese (Doutorado em Engenharia de Produção) - Programa de Pós-graduação em Engenharia de Produção - Universidade Federal de Santa Catarina, Florianópolis, 2004. 
MACULAN A. M; MERINO, J. C. Como avaliar a transferência do conhecimento na interação universidade-empresa? In: SIMPÓSIO DE GESTÃO DA INOVAÇÃO TECNOLÓGICA, 20., 1998, Resende. Anais... Resende: AEDB, 1998.

MAIA, M. das G.S.F. A integração universidade/ empresa como fator de desenvolvimento regional: um estudo da região metropolitana de Salvador. 2005. Tese (Doutorado em Administração) - Universidade de Barcelona, Barcelona, 2005.

MARCOVITCH, J. Industry-university interaction in a new world context: policy and action. Tecnology, Innovation \& Commercialization Series. Southbound: International Development Research Centre, 1996. $15 p$.

NAISBITT, J. O paradoxo global: quanto maior a economoia mundial, mais poderosos são os seus protagonistas menores. Rio de Janeiro: Campus, 1994.

PASSOS, C.F. Desafios para as pequenas e médias empresas. Folha de São Paulo, São Paulo, 17 jul. 1996, caderno 2.

PRADO, M. C. R. M. Dinamismo empresarial é freado ao nascer. Gazeta Mercantil. São Paulo. 03/01/2001. Caderno Análise \& Perspectivas. p. A-3.

PROEX/UFSCAR. Proposta de criação dos núcleos de extensão UFSCar-sociedade. São Carlos: Pró-Reitoria de Extensão/UFSCar, 1994. $22 \mathrm{p}$.

RIPPER FILHO, J. E. Ciência e Tecnologia: para quê? Como? In: MUSA, Edson Vaz et al. Ciência e tecnologia: alicerces do desenvolvimento. São Paulo: Cobra, 1994.

SÁBATO, J.; BOTANA, N. La ciência y La tecnologia em el dessarrollo futuro de América Latina. Revista de La Integración, ANDIMA, p. 19, nov. 1968.

SEBRAE-SP. Serviço Brasileiro de Apoio às Micro e Pequenas Empresas do Estado de São Paulo.

10 anos de monitoramento da sobrevivência e mortalidade de empresas. out./2008.
Disponível em: <http://www.sebraesp.com.br/ conhecendo_mpe/mortalidade $>$. Acesso em: 10 jun. 2009.

. Disponível em: <http://www.gerin. sebrae.com.br/site/na/conmpe.nsf > . Acesso em: 20 set. 1999.

SEGATTO-MENDES, A. P.; SBRAGIA, R. O processo de cooperação universidade-empresa em universidades brasileiras. Revista de Administração (USP), São Paulo, v. 37, n. 4, p. 58-71, 2002.

SILVA, F.L.E. Autonomia e interação. Revista USP, São Paulo, n. 25, p. 62-67, mar./maio 1995.

TORKOMIAN, A.L.V. Gestão de tecnologia na pesquisa acadêmica: o caso de São Carlos. 1997, . Tese (Doutorado em Administração)- FEA/ Universidade de São Paulo, São Paulo, 1997.

VELHO, S.M. Relações universidade-empresa em três estudos de caso: produção de ciência ou interesses de mercado? 1993, 227f. Tese (Doutorado em Administração), Universidade de Brasília, UnB, 1993.

WEBSTER, A. J.; ETZKOWITZ, H. Academicindustry relations: the second academic revolution? Science Policy Support Group, London, n.12, p.31, 1991.

ZAGOTTIS, D. L. de. Sobre a interação entre a universidade e o sistema produtivo. Revista USP, São Paulo, n. 25, p. 74-83, mar./maio 1995. 